ИЗВЕСТИЯ АКАДЕМИИ НАУК ЭСТОНСКОИ ССР. ФИЗИКА МАТЕМАТИКА PROCEEDINGS OF THE ACADEMY OF SCIENCES OF THE ESTONIAN SSR. PHYSICS * MATHEMATICS

$1988,37,2$

Г. АШКИНАЗИ, О. ЗОЛОТАРЕВСКАЯ, Л. ЗОЛОТАРЕВСКИИ, Л. МАЗО, Б. МЕИЛЕР, А. ПАДЬЮС

\title{
МАКРОДЕФЕКТЫ ЭПИТАКСИАЛЬНЫХ СЛОЕВ GaAs И ИХ ВЛИЯНИЕ НА НАПРЯЖЕНИЕ ПРОБОЯ СИЛОВЫХ ДИОДОВ
}

\author{
(Представил К. К. Ребане)
}

Основным элементом высоковольтных силовых полупроводниковых приборов на основе арсенида галлия (СП) является высоковольтный $p$-n-переход, получаемый в настоящее время в основном методом эпитаксиального наращивания $\left.{ }^{1}\right]$. Для получения напряжения пробоя $U_{B R}=10^{2}-10^{3}$ В необходимо обеспечить максимальную чистоту эпитаксиального слоя (ЭС) с уровнями легирования вблизи $p-n$-перехода $10^{14}-10^{15} \mathrm{~cm}^{-3}$ и соответственно ширину области объемного заряда 5-50 мкм $\left[{ }^{2}\right]$. Одним из перспективчых методов получения таких структур является выращивание их из тонкого слоя раствора-расплава GaAss в Ga, заключенного между двумя подложками, при программируемом охлаждении. Таким способом удается вырастить ЭС толщиной до 200-300 мкм, содержащие $p-n$-переходы с $U_{B R}$ до 2 кВ [ $\left.{ }^{3}\right]$. Необходимую концентрацию носителей можно обеспечить выращиванием слоев в кварцевой кассете поворотного типа. При этом, согласно $\left[{ }^{4}\right]$, в процессе выращивания, вероятно, происходит легирование кремнийкислородными комплексами и обычно (в зависимости от условий выращивания) $p$-n-переход образуется вблизи середины ЭС. Толщина ЭС, его чистота и соответственно напряжение пробоя $p$-n-перехода довольно жестко связаны с температурой начала эпитаксии $T_{\text {H. }}$. Показано, что для обеспечения высоких значений $U_{B R} T_{\mathrm{H}}$ должна быть $900-950^{\circ} \mathrm{C}\left[{ }^{5}\right]$.

Это специфическое сочетание условий выращивания ЭС существенно отличается от обычно используемых при эпитаксии соединений $A^{\mathrm{III}}-B^{\mathrm{V}}$ и приводит к тому, что и морфология, и структурные дефекты таких слоев достаточно специфичны и в литературе практически не описаны.

Вместе с тем очевидно, что для высоковольтных силовых приборов, рабочая площадь которых составляет от нескольких десятых долей до нескольких квадратных сантиметров, структурное совершенство ЭС имеет первостепенное значение, так как практически определяет воспроизводимость процесса и многие надежностные и эксплуатационные параметры прибора. Однако на современном уровне развития технологии наращивания возможности управления структурным совершенством ЭС ограничены и необоснованно высокие требования, предъявляемые к ним, приводят к уменьшению выхода годных приборов и к удорожанию их. Поэтому особое значение приобретает изучение влияния тех или иных структурных дефектов на величину $U_{B R}$ и разработка обоснованных критериев оценки качества и структурного совершенства ЭС. 


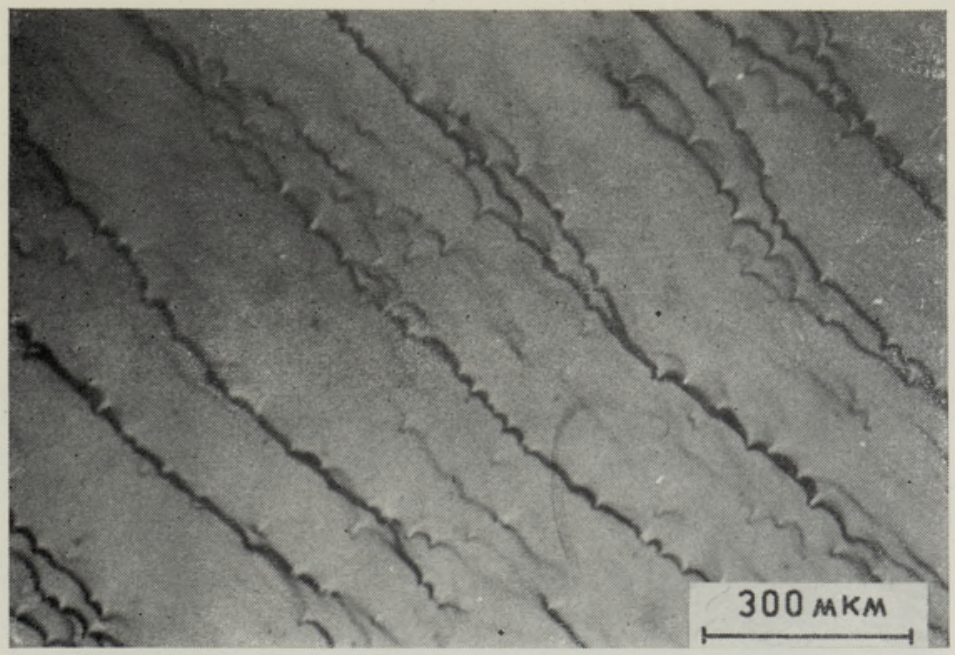

Рис. 1. Характерная морфология поверхности толстых ЭС.
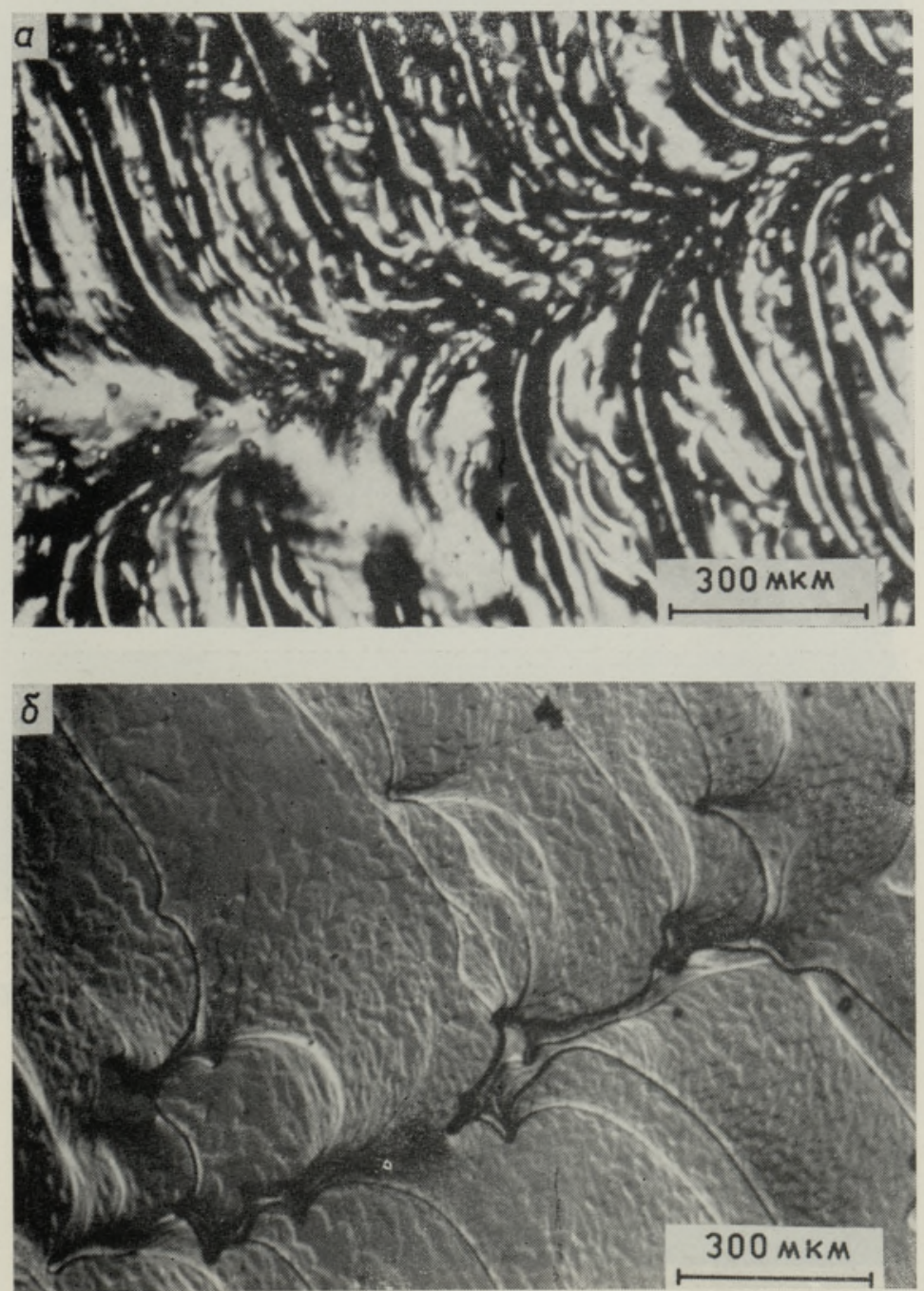

Рнс. 2. Наследование эпитаксиальным слоем царапин на подложке: $a-$ область $p$-n-перехода, б - поверхность ЭС. 

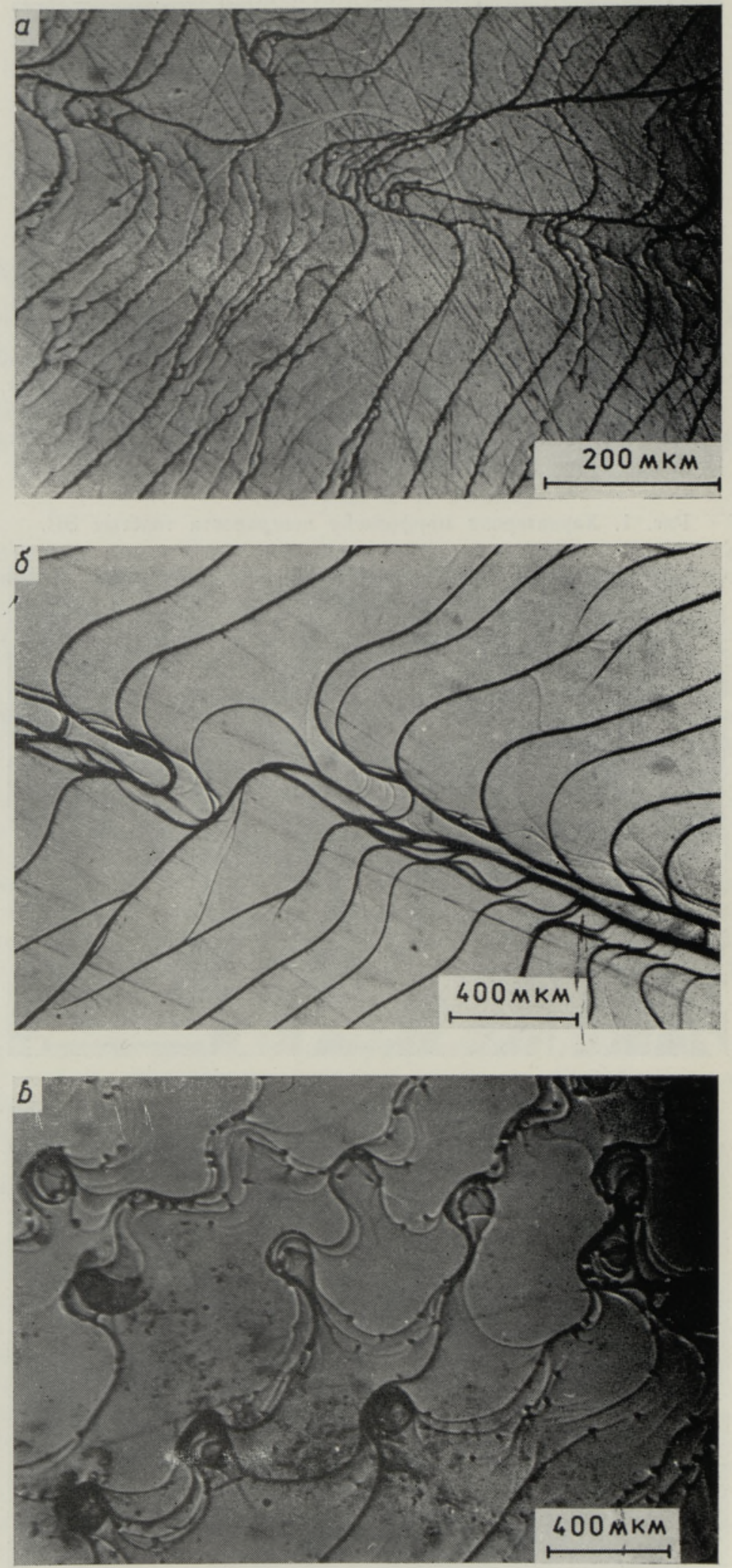

Рис. 3. Морфологические дефекты ЭС: $a-$ «ложбина», 6 - «канал», $в-$ «дыркнз, 

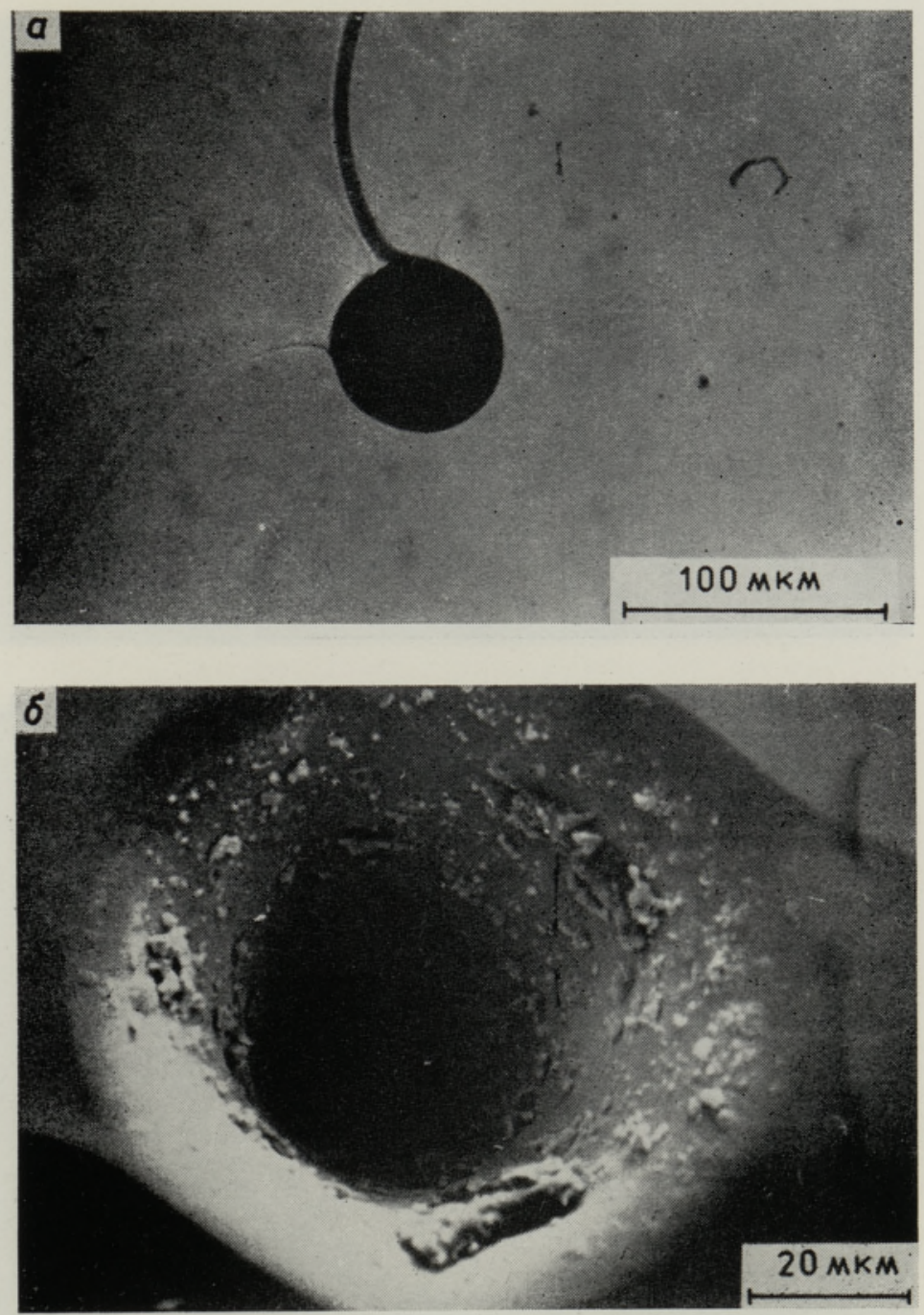

Рис. 4. Глубокая пора: $a-$ оптическая микрофотогрзфия, б- изображение в растровом электронном микроскопе. 

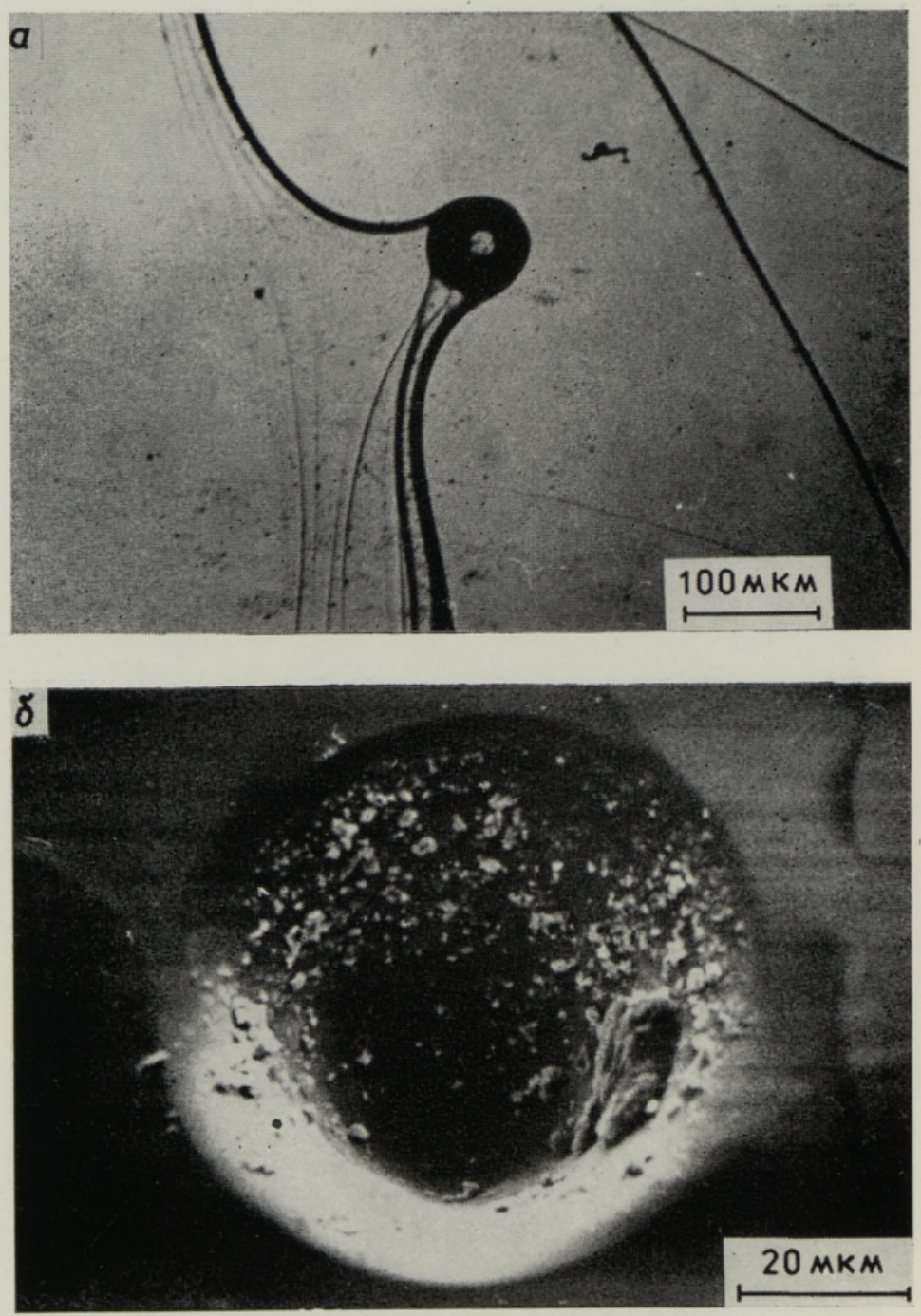

Рис. 5. Неглубокая пора с видимым дном: $a$ - оптическая микрофотография, $\sigma$ изображение в растровом электронном микроскопе. 

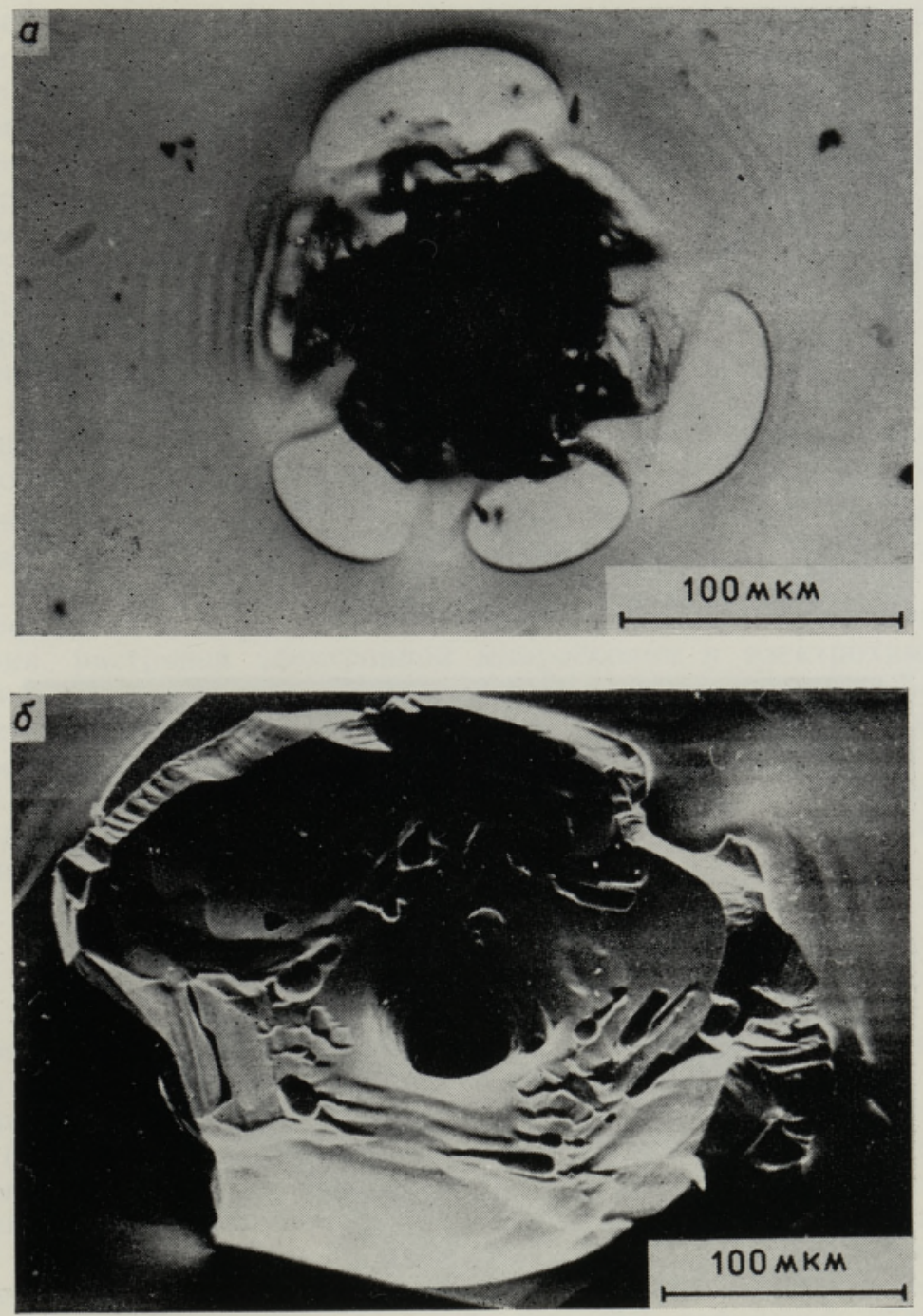

Рис. 6. «Большой дефект»: $a-$ оптическая микрофотография, $6-$ изображение в растровом электронном микроскопе. 

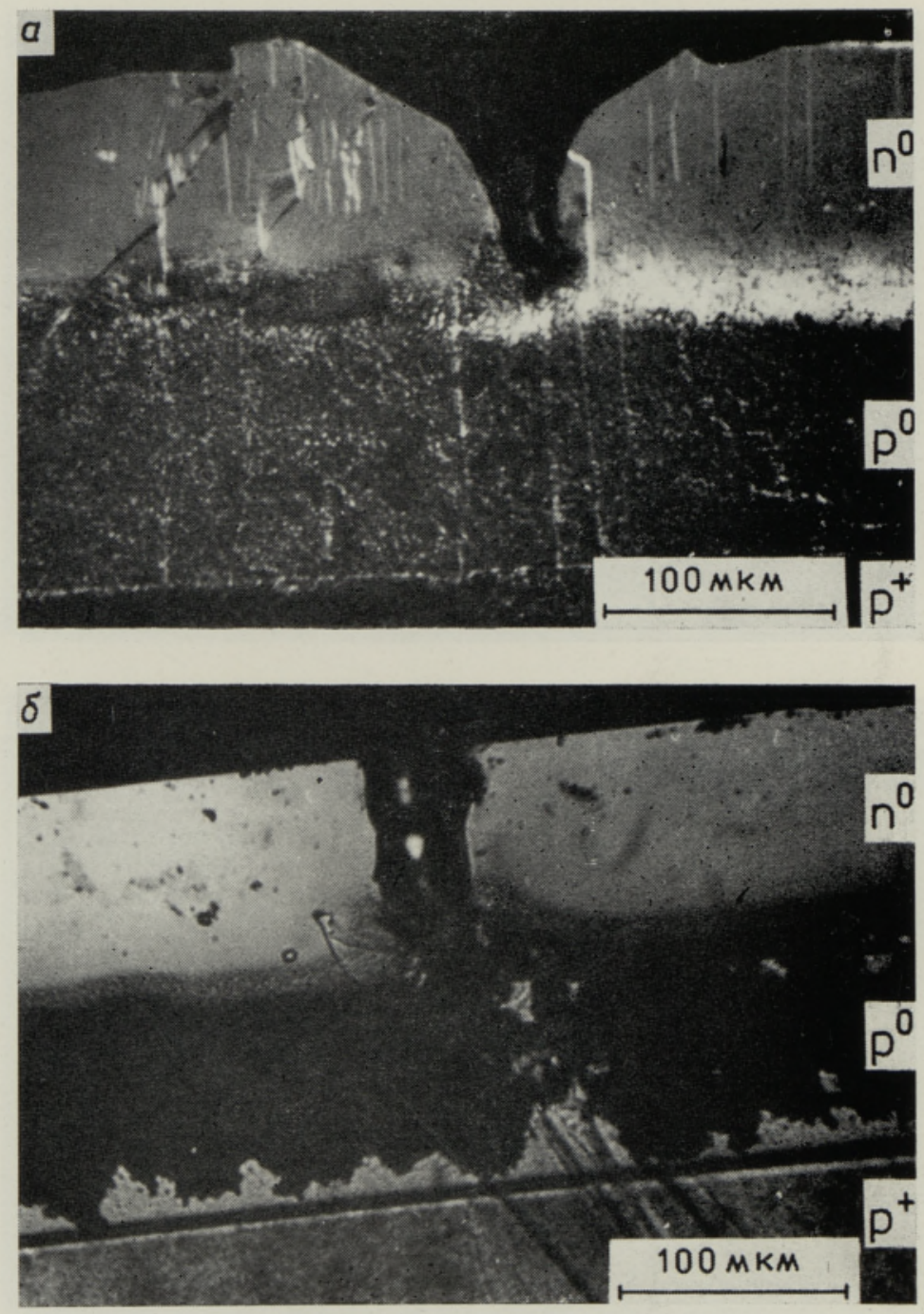

Рнс. 7. Окрашенные сколы черсз поросодержащие дефекты: $a$ - «большой дефект», $\sigma$ - пора. 
Цель настоящей работы состояла в изучении морфологии и макродефектов толстых ЭС арсенида галлия и в выяснении их влияния на напряжение пробоя силовых диодов.

\section{Методика эксперимента}

ЭС арсенида галлия толщиной около 150 мкм выращивали методом программированного охлаждения тонкого слоя раствора-расплава $\mathrm{GaAs}$ в галлии с $T_{\mathrm{H}}=950{ }^{\circ} \mathrm{C}$ в кварцевой кассете поворотного типа. Толщина зазора между подложками составляла 1,4-1,6 мм, скорость программированного охлаждения $0,5 \mathrm{~K} /$ мин. Наращивание вели на легированные цинком подложки арсенида галлия ориентации (111) $B$ диаметром около 30 мм, прошедшие стандартную полировку и непосредственно перед процессом - травление в сернокислотном травителе на глубину нескольких микрометров. Далее, из пластин вырезали диски диаметром 6,6 мм, которые разбраковывали по дефектности и после никелирования, пайки к термокомпенсаторам и травления боковой поверхности получали диодные структуры. Оценка влияния дефектов велась не по абсолютной величине $U_{B R}$, а по его отношению к расчетному значению для данной конкретной структуры. Расчетную величину $U_{B R}^{0}$ получали на основании вольт-фарадных измерений структуры по методике $\left[{ }^{6}\right]$. Разбраковку структур по дефектности вели при небольшом увеличении, поэтому размер изучавшихся дефектов составлял от единиц до сотен микрометров.

Морфология и дефекты ЭС изучались методами оптической металлографии, растровой электронной микроскопии и электрохимического травления. Глубина залегания дефектов определялась по сколу после его электрохимического окрашивания. Несколько видоизмененный метод послойного электрохимического травления $\left[{ }^{7}\right]$ позволил нам, послойно удаляя подложку и $p^{0}$-слой, достаточно точно выходить в область $p$ - $n$-перехода, одновременно металлографически фиксируя изменение дефектности структуры.

\section{Морфология ЭС}

Основным морфологическим признаком толстых ЭС является довольно сильно развитый рельеф поверхности в виде волн роста, определяемых торможением на стопорах эшелонов движущихся ступеней роста (рис. 1). Природа стопоров пока не установлена и они в дальнейшем нами не рассматриваются, так как относятся, скорее, к микродефектам. На степень развитости рельефа и его форму существенно влияет качество подготовки поверхности подложки. Так, механические нарушения, царапины и т. п., препятствуя нормальному слоевому росту, определяют прорастание через весь ЭС дефектной области. На рис. 2 приведен пример «проросшей царапины». Значительную роль в развитии рельефа играют и температурные градиенты в печи. Увеличение радиального градиента до нескольких градусов на сантиметр приводит к формированию очень грубого рельефа. Необходимо также следить за строгой горизонтальностью пластин в печи. Вместе с тем, как показывает изучение окрашенных сколов, границ раздела ЭС-подложка и $p$ - $n$-перехода, неоднородности подложки не определяют полностью рельеф поверхности ЭС. Существенные возмущения фронта роста могут возникать на стадии образования $p$-n-перехода. Это подтверждается как непосредственно при послойном электрохимическом травлении структур со стороны подложки, так и косвенно, по тому

7 ENSV TA Toimetised. F* M 21988 
факту, что слои, выращенные без $p$-n-перехода $\left(p^{+}-p^{0}\right.$; такие слой можно получать, несколько меняя газовые потоки в печи), имеют обычно более гладкую поверхность, чем $p^{+}-p^{0}-n^{0}$-структуры. Причина возмущений фронта роста вблизи $p$ - $n$-перехода пока неизвестна.

Обычно высота рельефа составляет от долей до единиц микрометров, в редких случаях очень грубой морфологии достигая нескольких десятков микрометров. Достаточно часто ступени роста при возмущениях своего латерального движения образуют характерные макродефекты: «ложбины» (рис. 3, $a$ ), «каналы» (рис. $3, \sigma)$, «дырки» (рис. 3, в) и т. д.

Другим характерным дефектом толстых ЭС являются поры и связанные с ними «большие дефекты». Поры (рис. 4, $a, \sigma)$ представляют собой просто отверстия в ӘС и бывают разной глубины, иногда с видимым дном (рис. $5, a, \sigma)$. Они могут быть как связаны с другими макродефектами, обычно следами царапин и «каналами», так и находиться на совершенно гладкой поверхности. «Большие дефекты» всегда содержат одну или несколько пор, окруженных поликристаллическими наростами (рис. 6, $a, 6)$.

Определение глубины этих дефектов показало, что чаще всего они зарождаются вблизи $p$-n-перехода (рис. $7, a, 6)$, хотя бывают как более мелкими (обычно поры), так и более глубокими, видимо доходящими до подложки. Тщательное металлографическое изучение при послойном стравливании со стороны подложки не выявило никаких особенностей, с которыми можно было бы связать образование пор и «больших дефектов». Не было обнаружено ни крупных выделений, ни скоплений дислокаций или других дефектов ни под, ни вокруг вершины отверстий. По-видимому, образование этих дефектов, как и грубого рельефа, связано с нарушением устойчивости фронта роста при образовании $p-n$-перехода, которое приводит к захвату раствора-расплава и дальнейшему росту сплошного канала до поверхности.

\section{Взаимосвязь морфологических дефектов с напряжением пробоя силовых диодов}

Влияние морфологических дефектов на $U_{B R}$ в первую очередь зависит от их глубины проникновения. Так как при никелировании осаждение металла происходит и на внутренней поверхности пор и поросодержащих дефектов, то если отверстие проникает глубже $p-n$-перехода, последний оказывается после создания контакта закороченным. При глубине дефекта меньше глубины залегания $p$ - $n$-перехода вблизи вершины дефекта происходит перераспределение поля объемного заряда, приводящее, в свою очередь, к снижению $U_{B R}$. Если же дефект не доходит до области объемного заряда даже при максимальном его расширении, то, очевидно, на величину $U_{B R}$ он влияния не оказывает.

Действительно, в партии диодных структур, забракованных из-за наличия на них поросодержащих дефектов, только около половины оказались короткозамкнутыми, остальные имели значение $U_{B R}$, близкое к значению $U_{B R}$ для бездефектных структур.

Наблюдаемый разброс глубины проникновения дефектов и трудности ее определения выдвинули задачу нахождения оптимальной глубины $p$ - $n$-перехода (толщины $n^{0}$-слоя), при которой влияние дефектов будет минимальным. Подобный подход к увеличению выхода высоковольтных структур кажется естественным, если принять, что причиной возникновения макродефектов служат все же дефекты подложки и начальные стадии формирования ЭС. Тогда удаление от дефектного переходного слоя будет улучшать структурное совершенство $p$ - $n$-пе- 
рехода. Вместе с тем, существенное уменьшение толщины $n^{0}$-слоя приводит его в опасную близость с дефектами поверхности ЭС, что, в свою очередь, может вызвать снижение $U_{B R}$. Значительное же увеличение общей толщины ЭС тоже нежелательно, так как увеличивает падение прямого напряжения на структурах и существенно усложняет сам процесс эпитаксии.

Для определения оптимальной толщины $n^{0}$-слоя нами были построены гистограммы распределения процента выхода структур $(D)$ с напряжением пробоя равным расчетному, т. е. $U_{B R}=U_{B R}^{0}$, и гистограммы распределения процента короткозамкнутых структур в зависимости от толщины $n^{0}$. Гистограммы были построены отдельно для бездефектных структур и для структур с морфологическими дефектами. Для этого перед металлизацией была проведена разбраковка по внешнему виду (по признаку бездефектная-дефектная) и для каждой структуры по химически окрашенному осколку от вырезки определена толщина $n^{0}$-слоя. Объем выборок - около 500 структур в каждой. Гистограммы (рис. 8) показывают, что для структур без видимых морфологических дефектов величина $D$ мало зависит от толщины $n^{0}$ и составляет в среднем $60-65 \%$; имеется слабая тенденция к росту $D$ с увеличением толщины $n^{0}$. Процент выхода короткозамкнутых структур (рис. 8, б) несколько уменьшается при толщинах $n^{0}$ выше 70 мкм. Для структур с морфологическими дефектами $D$ существенно ниже (рис. $8, a)$ (около $30 \%$ ) и увеличивается до $40-60 \%$ только при толщинах $n^{0}$ выше 90 мкм. Процент короткозамкнутых структур остается высоким (около 35-40\%) до толщины $n^{0} 90$ мкм, падая до $10-15 \%$ для более толстых слоев.
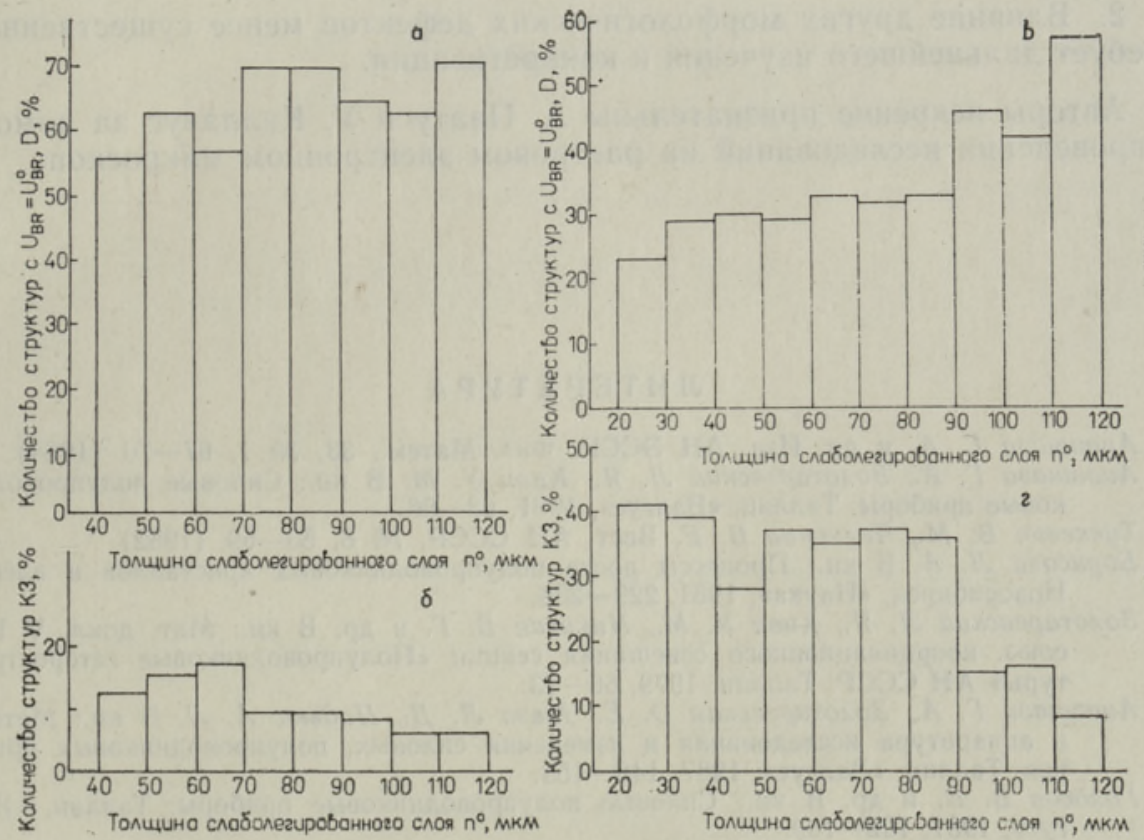

Рис. 8. Гистограммы распределения процента выхода $D$ структур с $U_{B R}=U_{B R}$ и короткозамкнутых (КЗ) от толщины $n^{0}$-слоя: $a$ - бездефектные структуры с $U_{B R}=U^{0}{ }_{B R}, 6-6$ - бдефектные структуры, короткозамкнутые, $\boldsymbol{\theta}$ - дефектные структуры с $U_{B R}=U_{B R}, 2-$ дефектные структуры, короткозамкнутые. 
Остальные структуры имеют пониженное напряжение пробоя, что может быть связано с локальными колебаниями уровней легирования слоев и(или) с влиянием дефектов, сужающих, но не закорачивающих область объемного заряда.

Некоторое увеличение выхода годных структур при очень толстых $n^{0}$-слоях связано, видимо, с залечиванием дефектов и более высоким структурным совершенством толстых ЭС. Однако при этом общая толщина ЭС становится слишком большой, не менее 250-300 мкм.

Для проверки влияния морфологических дефектов на $U_{B R}$ были проанализированы дефектные (короткозамкнутые) диодные структуры. С них были удалены термокомпенсаторы, поверхность ЭС очищена травлением и просмотрена под оптическим микроскопом. На структурах в основном были обнаружены «большие дефекты», поры и очень развитый рельеф поверхности. При помощи химически стойкого лака и травления на поверхности ЭС были сформированы «дефектные» (содержащие морфологический дефект) и бездефектные мезаструктуры. Измерение на них величины $U_{B R}$ показало, что бездефектные мезаструктуры всегда имеют $U_{B R}$, близкое к расчетному, тогда как «дефектные» мезаструктуры, как правило, оказываются короткозамкнутыми. K короткому замыканию приводят в основном поросодержащие дефекты.

\section{Выводы}

1. Описаны морфология и морфологические дефекты толстых ЭС арсенида галлия. Показано, что значительный вклад в формирование морфологии поверхности ЭС вносит стадия образования $p-n$-перехода. $\mathrm{K}$ закорачиванию $p$-n-перехода приводят, как правило, поросодержащие дефекты.

2. Влияние других морфологических дефектов менее существенно и требует дальнейшего изучения и конкретизации.

Авторы искренне признательны А. Паату и У. Каллавус за помощь в проведении исследований на растровом электронном микроскопе.

\section{Л И ТЕ Р А Т У Р А}

1. Аикинази Г. А. и др. Изв. АН ЭССР. Физ. Матем., 33, № 1, 67-76 (1984).

2. Аикинази Г. А., Золотаревский Л. Я., Киви У. М. В кн.: Силовые полупроводниковые приборы. Таллин, «Валгус», 1981, 63-66.

3. Тучкевич В. М., Челноков В. Е. Вест. АН СССР, № 8, 53-59 (1982).

4. Борисова Л. А. В кн.: Процессы роста полупроводниковых кристаллов и пленок. Новосибирск, «Наука», 1981, 229-236.

5. Золотаревский Л. Я., Киви У. М., Никитин В. Г. и др. В кн.: Мат. докл. V Всесоюз. координационного совещания секции «Полупроводниковые гетероструктуры» АН СССР. Таллин, 1979, 66-73.

6. Аикинази Г. А., Золотаревская О. Е., Мазо Л. Д., Падьюс А. Л. В кн.: Методы и аппаратура исследования и измерения силовых, полупроводниковых приборов. Таллин, «Валгус», 1987, 148-153.

7. Голосов В. В. и др. В кн.: Силовые полупроводниковые приборы. Таллин, «Валгус», 1981, 102-109.

Научно-исследовательский институт

Таллинского электротехнического

Поступила в редакцию завода им. М. Н. Калинина

$21 /$ XI 1986

Таллинский политехнический институт 
G. ASKINAZI, O. ZOLOTAREVSKAJA, L. ZOLOTAREVSKI, L. MAZO, B. MEILER,

A. PADJUS

\section{GaAs EPITAKSIAALKILEDE MAKRODEFEKTID JA NENDE MOJU JOUUIOODIDE LÄBILÖÖGIPINGELE}

On kirjeldatud paksude GaAs autoepitaksiaalkilede makrodefekte ja uuritud nende mõju jõudioodide läbilöögipingele. On kindlaks tehtud, et $p-n$ siirde tekkimise staadium mõjutab o'uliselt epitaksiaalkilede morfoloogiat ja defektsust, ning näidatud, et kõige ohtlikumad on poore sisaldavad defektid, mis ulatuvad ruumlaengu piirkonda.

G. ASHKINAZI, O. ZOLOTAREVSKAYA, L. ZOLOTAREVSKI, L. MAZO, B. MEILER, A. PADIUS

\section{MACRODEFECTS IN GaAs LPE LAYERS AND THEIR EFFECT ON THE BREAKDOWN VOLTAGE OF POWER DIODES}

The macrodefects in the thick GaAs LPE layers and their effect on the breakdown voltage of power diodes are described.

The growth step of $p-n$ junction formation has a strong influence on the epitaxial layer morphology and defects. The pore containing defects if they penetrate $p-n$ junction, are the most dangerous ones. 